\title{
What Are Essential Elements of Valid Research: The Problem of 'Data' and Their Collection in Cross-Cultural Contexts
}

\author{
Judith K. Bernhard
}

Ryerson University

Please Cite:

Bernhard, J. K. (2010). What are essential elements of valid research: The problem of 'data' and their collection in cross-cultural contexts. Perspectives: Canadian Association of Family Resource Programs, 3(Spring), 27-32.

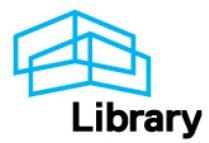




\title{
What are the Essential Elements of Valid Research? \\ The Problem of "Data" and their Collection in Cross-Cultural Contexts
}

\author{
Judith K. Bernhard, Ph.D.
}

\begin{abstract}
$\nabla$ Abstract
Professor Judith Bernhard teaches in the School of Early Childhood Education at Ryerson University. She draws on her own experience of research in the field of transnational families to illustrate the challenges of collecting data that can inform practice in the field. She begins by outlining her own personal history as an immigrant and an academic. The difficulties of attempting to be both an advocate for families and a scholarly investigator touch her personally. She uses two cases to illustrate some of these difficulties. The first is the case of divergent perspectives on the role of a parent in the case of a young adolescent whose family had come to Canada from El Salvador. The girl's teacher and her family differed in their views on her rights and responsibilities, based on their cultural values. Dr. Bernhard describes how these different views were also represented among the members of the research team. Her own roots in South America gave her an understanding of the family's position, while her academic training allowed her to sympathize with the teacher's purposes. The team wrote a report that did not fully reflect the tension between the cultures; however, Dr. Bernhard concludes that researchers need to be more mindful of their own professional training and acculturation as important markers to consider in the research process. The second case she presents raises the difficulties she encountered using interviews to investigate the lived experience of refugee Somali mothers. The first interviewer, although an experienced researcher with immigrant roots, proved unacceptable to the Somali families, mostly because he was male. The next person chosen came from the Somali community and was trained by the researchers to obtain informed consent and conduct standard interviews. Dr. Bernhard describes how cultural perceptions and norms made it impossible to use these standardized approaches with the population under investigation, meaning that no credible research paper on the findings could be published. This in turn meant that information about the families' situation and views would not reach professionals and policy makers whose decisions influence the families' lives. Dr. Bernhard encourages the research community to reflect on how to take cultural issues into consideration when deciding what is meant by significant "data" and the best methods for collecting them.
\end{abstract}




\section{My Subjective "I"}

Working across difference has been a necessary but also richly rewarding part of my life. I carry with me the experiences of border crossing as a family member, a student, a teacher, and a mother. At the moment, I am a Professor and Director of a Masters Program in Early Childhood Studies. I am also a migrant. Born in Chile, I have subsequently made my "home" in Puerto Rico, in the Dominican Republic, and in Canada.

Moving from continent to continent, learning new languages, new worldviews, and new sets of "core values" has helped me to see the arbitrary nature of the rules and regulations used to classify, sort, and manage people.

I have been the Principal Investigator of a number of projects designed to document the struggles migrant families go through as their children try to find the right balance between succeeding in North American schools while retaining their original cultural identity and language in the family. I and my co-workers on these projects have always aimed to capture the lived experience of our research "subjects" in such a way that we could change educational and political practices because of this knowledge. Thus, we have also intended our findings to support educators with the great challenges we know they face when working with students they perceive as different and often problematic.

In our work, we have made every effort to avoid a split between objective and subjective facts. We have sought systemic diagnosis of problems that reflect the lived experience of the persons we study. And we have done so because we believe that social knowledge is always situated and contextualized.

Thus, we have always appreciated the need for a diverse research team that can help shed light on the lived experiences of our participants. Team members from diverse backgrounds help the rest of the team understand the meanings that lie behind participants' words and actions. Our field is still at a stage where a multi-ethnic team needs to be intentionally selected and sometimes forcibly so because our institutions are not representative of all the groups we work with. My contribution to the present volume will focus on some of the challenges my colleagues and I have faced in working in multi-ethnic and multi-disciplinary teams.

What does "difference" mean to me? I have experienced ever-changing memberships and allegiances during the course of my life. In the words of Mary Catherine Bateson,

...membership is an artifact, something that has to be made... membership both acknowledges and bridges separateness, it is constructed across a gap of incomprehension, depending always on the willingness to join in and be changed by the common dance. (1994, p. 62)
Since coming to North America, I have been classified in many ways: as an immigrant, a tourist, an involuntary migrant, and, depending on which side of which border of the Americas I stand, as white or Latina or Hispanic. When I am in one place, I miss the values and ways of the other; yet when I actually go to that other place, I find it no longer exists as I remember it.

When I first immigrated to Canada, I wanted to adopt all that I saw as modern and progressive. Yet the result of this mindset was that often I felt that I had become a stranger to myself. Eva Hoffman describes a similar feeling in Lost in Translation. She describes how she left Cracow for Canada at age 13 and discovered that, after a short time, she had lost contact with her inner self:

The worst losses come at night. As I lie down in a strange bed in a strange house... I wait for the spontaneous flow of inner language which used to be my nighttime talk with myself and nothing comes. Polish, in a short time has atrophied, shriveled from sheer uselessness. Its words don't apply to my new experiences; they aren't coeval with any of the objects, or faces, or the very air I breathe in the daytime. In English, words have not penetrated to those layers of my psyche from which a private conversation could proceed... Now, this picture and word show is gone, the thread has snapped. I have no interior language. (Hoffman, 1990, pp. 107-108)

The challenges of holding onto a familiar subjectivity and at the same time feeling the pull and desire to assimilate to the new dominant order are strong and affect each aspect of my life to this day. As a researcher, I feel the difficulties of these pushes and pulls. I am honoured to have my voice heard by those in academia, yet it is difficult sometimes to switch from one voice to another as I attempt to be both family advocate and scholarly investigator.

Quantitative and data-driven approaches to social science have often been critiqued. Various alternatives have been proposed, including ethnographic approaches which are said to capture a reality that is not revealed in "hard data." However, as the examples below illustrate, there are problems of valid research methods and collection of data that can be considered "objective" (i.e., not merely the researcher's imaginings). The problems of obtaining informative and truthful answers from participants as well as those arising from the question of which answers ethically may be reported in research papers are not solved simply by resorting to ethnographic interviews.

\section{8 perspectives}


While the problems of interview data are not foreign to anthropologists, in the field of early childhood studies, the kinds of research issues we describe have not received very much attention. The extent to which early childhood researchers have their hands tied and their keyboards immobilized when it comes to investigating and giving reports on diverse families as well as making sure those investigations and reports meet the professional standards in social sciences has not been recognized.

I'd like to tell you about some of these issues by way of two stories. One involves a research project with Latina mothers. The other is a story about research with Somali mothers.

\section{Illustration One: Who can we represent? The story of Isabel}

The setting is an interview I am having with a teacher in a Toronto inner city school. We are talking about her student, 13-year-old Isabel Torres who was born in El Salvador and arrived in Canada at 10 years of age. I have been part of a team of participant observers in the school for two months, taking field notes and reviewing school records.

I also had the opportunity to visit the home of the Torres family on three occasions. The four Torres children live with their mother, father, and paternal grandmother in government housing. The father speaks English at a very basic level, the mother only Spanish. Mr. Torres works night shifts while the mother and paternal grandmother stay home with the children. The family speaks only Spanish at home, and Isabel's proficiency in Spanish is solid.

When discussing their values and family practices with me, Isabel's parents referred to family closeness as critical. They believe that it is key for parents to stay on top of their children's activities, to know where they are at all times, and to be aware of the issues the children are dealing with in their lives.

... in my view, one of the parents has to stay at home to be in touch with the children, to make sure they are eating well, and supervise what they are doing. My children come home every day for lunch... every day they have their soup... Now my older son is in high school so he can't come home but I have a friend who has a restaurant and he goes there to eat lunch every day.

During a separate interview, Isabel's teacher talks to me. She describes Isabel as a strong student, who is self-centred and excelling in all subjects. Nevertheless, it is clear from the teacher's words that Isabel's parents' values conflict with those of the teacher. The teacher says:

... I think that Isabel is very afraid of the consequences at home... which may make her behave well... so I am very cautious about what I tell them. The father is always at the school, he picks them up for lunch. I think there is so much control. He has this attitude, you know, like he is the one that rules everything. Even the mother seems terrorized. He has her, as they say, barefoot and pregnant in the kitchen, so how can she help her children? Just the other day I heard [from her father] that Isabel had written something in a journal about a boy who asked to kiss her. Her diary is confidential.... He shouldn't be reading this... Now he wants to know the name of the boy.

\section{Unpacking Illustration One: Within-community differences}

These above data resulted in a lengthy discussion among the research team on this project. The team consisted of three women and two men. The women included me, a woman from Ghana, and a European-Canadian woman. One of the men was European American and one was from Ghana. Our team agreement was that the process of data analysis would be conducted through our discussion sessions. This approach was new to me since, even when working in collaboration with others, I had always had the experience of dividing tasks and working alone on my little piece. The so-called reality of the situation of the Torres family is explored in terms of the subject positions of those in the research team. What is to be reported?

Some of the team members saw Isabel as a child at risk. According to them, she was someone afraid of the scare tactics of an authoritarian father. The family's close involvement in each other's affairs was perceived as intrusive and mean spirited in this view. The researchers felt that the young adolescent had a number of individual rights and that her development as an individual was crucial. They saw her as already close to a full-fledged person capable of making her own decisions. It follows from this that these team members would see adults' attempts to interfere, even if those adults were her own parents, as improper and oppressive.

Other team members saw the father's role as normal in his cultural context. They saw Isabel, on the other hand, as exemplifying the virtues of a bicultural approach. These researchers said that the father seemed un-cooperative. It is important to see the judgment behind such a term as 
"un-cooperative," however. It suggests that the father's wishes were at odds with those of the teacher and that the teacher was applying a universal template to Isabel. For example, the teacher appeared to be saying, "Here is a teen, these are her developmental tasks (a budding adult who needs freedom). She needs a desired family model that is democratic and child centred."

Looked at another way, however, we can see that the father's posture was not simply in opposition to the teacher. Rather, it was also a source of the family strength. Given the authority structure of the family, the "rights" of the minor dependant become of minimal concern in this model. Instead, the concern focuses on the welfare of the family, including the welfare of its minor members. A child of 13 is not of an age to make decisions about matters such as dating. A parent's role is to teach, guide, and protect the child.

I was concerned also about the teacher's role. In conveying her views to Isabel, she was affirming her own authority and in the process undermining the authority of Isabel's father. There was a potential for the emotional disruption of the family. If the teacher succeeded in arming Isabel with assertive views about her rights, she would be placed on a collision course with her father and the rest of her family. In other words, a seemingly small item such as stopping the father from reading the diary could have a devastating effect on the structure of the family.

In our team discussions about this case, I and my colleagues quickly realized that our two different views could not be entirely integrated or made consistent. All eyes turned to me as the Latina member of the team. Yet I found I was (and still am) of two minds: One reaction comes from my worldview as a fellow Latina, sharing the mother's goal of trying to adjust to life in Canada and maintaining her culture and values, and keeping her family together. I recognize the teacher was drawing on stereotypes of the Latino family, particularly, Catholic values about family, birth control, and abortion. I ask myself, if the father is a daily visitor to the school, why can't this teacher find strengths in the family and improve relations with them. Why all this mistrust on both sides?

I also hear the teacher through the lens of a middle-class woman with many years of education, a feminist who has chosen a career path, and someone who values privacy and children's rights. The experience of being trained for so many years in Euro-American post-secondary institutions has made me let go of my relational view of the world. I am now a professional, abiding by laws of mandated reporting. Although the family appreciates that I speak their language, there is a distance here that cannot be ignored.

In our team debriefing sessions, we reminded each other that there can be no context-free judgment of Isabel's father. We realized that even though we often thought of differences of gender and class, we need to be more mindful of our own professional training and acculturation as important markers to consider in the research process. It seemed to me that the family's structure should be understood and respected. I leaned toward the side of the family in the conflict. At the same time, I am aware of the teacher's concerns. Having been a teacher myself, I am familiar with "wanting what is best for the child" and advocating for a child by giving her a voice. Yet, I don't feel that a teacher's proper role is to take over or upgrade a child's position in the family in such a way that it could only have an unfavourable impact on the child. The ability to see conflicting worldviews and perspectives put me at a distance from Isabel and her family, and I had to wrestle with the responsibility of being the Latina on the team.

The role reversal that children in Isabel's case could potentially experience would make their learning difficult. In addition, it would mean that everyone who works in schools must be conscious of what is happening with the entire family as they educate the individual child. We perhaps have to live with the knowledge that the effect of some of our practices is that family boundaries are permeated, sometimes brutally shattered.

The reports that I and my team authored at the end of this project turned out to be sympathetic to Isabel's family's concerns. What the reports did not reflect, however, was the tension between the two cultures (as represented by the Torres family and Isabel's teacher) and between the varying views of the research team. Some issues are apparent to me now that were not my focus at the time. The issue of what is right for any given child is not such an objectively answerable question as one might think.

\section{Illustration Two: What counts as "Data"? The Somali Mothers Project}

The setting is a research team meeting in a school that has recently experienced a large influx of Somali families. The 
families were admitted to the country as political refugees because of civil unrest. They live in a block of apartment buildings in a suburb close to the Toronto International Airport.

The population of the school has changed dramatically and many of the teachers feel at a loss for knowing how to relate to the families. Our research project is aimed at shedding light on the lived experiences of the mothers whose children attend the school. As with all projects, we are on a timeline, and must abide by institutional policies such as Ethics Review committees, as well as interim and final reports.

Our first choice for the person to conduct the interviews is a Black Caribbean man. He has substantial training in qualitative methods and has written a great deal in this area. Very early on, we realize that the men are uncomfortable with him interviewing their wives; he asked his sister to go with him to interviews, but still the mothers were not comfortable talking to a man. We quickly realized gender issues were involved and so needed to regroup.

Through contacts with community groups we were able to hire Hafeezah, a Muslim woman who was working as a translator at a community center. In addition to a tape recorder, informed consent forms, and an interview protocol, we provided Hafeezah with previous articles we had written, elaborated on the research questions and the theoretical frameworks used. Further, we engaged in a number of scenarios and role plays.

At our third weekly research meeting, Hafeezah told us all was not well out in the field. She actually felt fearful for her life. She reported that many women would not talk to her because she did not wear a head covering. After long deliberations, we decided that our study would focus on the people who did agree to talk to her. Those who did invite Hafeezah into their home wanted to spend time talking about people they knew in common. She was expected to attend family events, accompany them to the doctor and drink lots of tea.

She related that given these families' experiences at home where the government threatened and harmed people, they were alarmed at the suggestion that someone associated with the school wanted them to sign papers, take notes, and audio-tape their responses. It would be counterproductive to raise any interview questions until the families could situate her and make sure that she was not on the wrong side of the political spectrum.

We are now six weeks into the data collection and need to write an interim report to the funder. I am meeting with Hafeezah to debrief on her interviews with the families:

Me: $\quad$ Hafeezah, now that you have had time to establish rapport with some of the families,
I want to know what they said so let's begin to debrief around the audio-tapes.

Hafeezah: There are no audio-tapes. The mothers come from situations where they have been betrayed so many times; they would feel insulted and suspect me as an intruder and informant, it is not appropriate. But I can tell you what they said. Just ask me.

Me: $\quad$ Let's go over the signed consent forms then. Maybe we can take your accounts and do a member check with the families. What quotes do you have from your notes? We still need actual quotes to be able to separate what actually happened from your interpretation.

Hafeezah: Taking notes or having them sign strange forms would be also disrespectful. I brought no pen or paper. We don't sign things like that. But I did jot down some notes after I got home and I remember what they said.

It was at this point that I realized how much I had assumed of Hafeezah and her world view. I realized the need for clear research guidelines. The concept of requiring some accountability for the world of researchers was not in Hafeezah's world view.

I then asked her to tell me her stories. She told me that many of the conversations focussed on situations of conflict with their children. When parents tried to set limits and enforce order and respect, the children threatened to call 911. There were many stories of children being taken away by Children's Aid societies, but due to the promises of confidentiality she had made to the families, she could not give us any more details. Hafeezah felt her life would be at risk if she were to betray this promise.

\section{Unpacking Illustration Two}

I was very frustrated at not being able to access these important data. This situation raised questions about quality and ethics of what we call research.

My first lesson with the Caribbean-Canadian researcher was that using only race as an identifier would not lead to meaningful findings. Rather, the in-group characteristics to be considered were gender, religion, culture and level of acculturation.

My second lesson had to do with revisiting my assumptions about what I call data or research. In our work we were committed to working with the University's rules for ethical con- 
duct of research with human subjects. We needed to have signed or verbal consents and data objective enough to allow for corroboration. ${ }^{1}$ Yet our demand for data and for their being collected in a certain way led to a stalemate.

We needed to get involved with participants' lives, yet we were imposing Western ways of thinking about time and about having discussions that became barriers to genuine understanding. Turning on the tape recorder could be conceptualized in Bourdieuian terms as symbolic violence. It was becoming clear to me that the interviews Hafeezah had conducted would not provide any usable material for a publishable paper in social sciences. This is not merely unfortunate as a research problem but it is truly unfortunate in that the situation of the families and the families' views would not be communicated to the outside world, to professionals in the field, and to policy-makers. While the research protocols of the university were designed to protect families, the upshot in this case was to remove them from being considered as participants in educational research. This is not a suggestion to undermine the protective goal of university research-ethics guidelines; one cannot simply remove protections.

In being faced with the challenge of balancing the vulnerability of the families and the need for educators to gain an understanding of the lived reality of the children and families, I have broadened my conceptions of what research is and the kind of team relationships we need to conduct the work. I find that traditional methodology is limited and that in order to obtain authentic responses, much rethinking is needed.

\section{Conclusion}

As researchers we experience dilemmas and there are no easy resolutions. We have shown how the problems of researching diverse families are not simply a matter of choosing between qualitative or quantitative methods, between detached or participatory approaches, or even between in- group, out-group researchers. We have looked at two examples and see that the research issues are not resolved by a decision to choose the "correct" alternative of the dichotomy.

As pointed out by Reid and Tom (2006), in asking people to tell their stories to researchers, we are making an implicit promise to do something with their stories. Yet if the research team cannot agree on the essential elements that have to be present for the report of a story to be acceptable as "data," we are doing an injustice to the family.

This is not a paper with simple answers for complex problems. What I recommend is that researchers undertake to reflect on these problems. The issues deserve more airing in professional forums. We should not hold back on grounds that we appear not to be totally in command; we need some humility and realism about the limitations of present approaches.

I leave readers with the question of what aspects or modes of investigation are essential in order for us to call a report of someone's experiences or of a series of events, "data." We need to consider how to capture the lived experiences in ways that are considered useful, and of sufficient genuineness or "objectivity" as to be a basis for our changing our practice because of what we have learned.

Dr. Judith K. Bernhard is a professor in the School of Early Childhood Education at Ryerson University in Toronto and Program Director for the Masters in Early Childhood Studies. Her research has focussed on early childhood education and care settings with an emphasis on how the early childhood education field responds to inclusion and diversity. Dr. Bernhard is engaged in studies of transformative family literacy, transnational families and collaborative work between early childhood personnel and families.

\section{References}

Bateson, Mary Catherine (1994). Peripheral visions: Learning along the way. New York: HarperCollins.

Hoffman, Eva (1990). Lost in translation: A life in a new language. NY: Penguin Books.

Reid, Colleen and Allison Tom (2006). Poor women's discourses of legitimacy, poverty, and health. Gender $\mathbb{E}$ Society 20(3), 402-421.

1. Ethics Review Boards allow researchers to offer participants their choice of a verbal or written consent process, following established procedures. On this subject, see Bernhard, J. K., Young, J. E. E. (2009). Gaining institutional permission: Researching precarious legal status in Canada, Journal of Academic Ethics, $7(3), 175-191$.

\section{2 perspectives}

